\title{
Mechanical Properties of Laser-Sintered 3D-Printed Cobalt Chromium and Soft-Milled Cobalt Chromium
}

\author{
Abdullah Barazanchi * (D), Kai Chun Li, Basil Al-Amleh, Karl Lyons and J. Neil Waddell \\ Department of Oral Rehabilitation, Sir John Walsh Research Institute, Faculty of Dentistry, University of Otago, \\ Dunedin 9054, New Zealand; Kc.li@otago.ac.nz (K.C.L.); alamleh@gmail.com (B.A.-A.); \\ karl.lyons@otago.ac.nz (K.L.); neil.waddell@otago.ac.nz (J.N.W.) \\ * Correspondence: abdullah.barazanchi@otago.ac.nz; Tel.: +64-034798889
}

Received: 7 September 2020; Accepted: 9 October 2020; Published: 12 October 2020

\begin{abstract}
Purpose: To compare the mechanical properties and fracture behaviour of laser-sintered/3D-printed cobalt chromium ( $\mathrm{LSCOCr}$ ) with soft-milled cobalt chromium (SM CoCr) to assess their suitability for use in high-stress areas in the oral cavity. Material and Method: Two computer-aided manufacturing methods were used to fabricate dumbbell specimens in accordance with the ASTM standard E8. Specimens were fractured using tensile testing and elastic modulus, and proof stress and ultimate tensile strength were calculated. Fracture surfaces were examined using scanning electron microscopy. Plate specimens were also fabricated for the examination of hardness and elastic modulus using nanoindentation. Unpaired $t$-test was used to evaluate statistical significance. Results: LS CoCr specimens were found to have significantly higher ultimate tensile strength (UTS) and proof stress (PS) $(p<0.05)$ but not a significantly higher elastic modulus $(p>0.05)$. Examination of the dumbbell fracture surfaces showed uniform structure for the LS CoCr specimens whilst the SM CoCr specimens were perforated with porosities; neither showed an obvious point of fracture. Nanoindentation also showed that LS CoCr specimens possessed higher hardness compared with SM CoCr specimens. Conclusion: LS CoCr and SM CoCr specimens were both found to exhibit uniformly dense structure; although porosities were noted in the SM CoCr specimens. LS CoCr specimens were found to have superior tensile properties, likely due to lack of porosities, however both had mean values higher than those reported in the literature for cast CoCr. Uniformity of structure and high tensile strength indicates that LS CoCr and SM CoCr fabricated alloys are suitable for long-span metallic frameworks for use in the field of prosthodontics.
\end{abstract}

Keywords: 3D printing; soft milling; cobalt chromium; modulus of elasticity; prosthodontics

\section{Introduction}

Dental prostheses require a material with minimum physical properties to be able to function structurally in the harsh oral environment. High-strength substructures are becoming more in demand with the increasing use of long-span frameworks in prosthodontics including tooth- and implant-supported prostheses [1]. Investigating the mechanical behaviour of various sub-structures is essential to be able to predict long-term success of a dental prosthesis [2]. Cobalt chromium ( $\mathrm{CoCr})$ is a common base metal alloy used in dental prostheses. Initially, $\mathrm{CoCr}$ alloys were associated with fabrication of metallic frameworks in removable prosthodontics; today its use is frequently extended to fixed prostheses. The primary reason for the increase of use of $\mathrm{CoCr}$ is due to the lower cost of frameworks fabricated with $\mathrm{CoCr}$ when compared with equivalent frameworks fabricated using noble or high noble metals [3,4]. Base metals have also been shown to meet the physical properties needed for use in high-functional-load cases, such as long-span bridges and implant frameworks, where superior mechanical properties are required $[5,6]$. However, traditional casting methods for $\mathrm{CoCr}$ frameworks 
are generally more difficult to manufacture due to having a high melting temperatures, reduced ductility and high hardness of the alloy [5,7]. This is coupled with the somewhat unpredictable nature of lost-wax technique in regards to homogeneity of the resultant structure, where structural defects can occur due to improper penetration of the alloy during casting [8]. Use of computer-aided manufacturing (CAM) methods has allowed for better control of macro- and microstructures in CoCr frameworks by manufacturers ensuring high control of block or powder during production [9]. Subtractive CAM techniques such as milling involve cutting of a prefabricated $\mathrm{CoCr}$ block down to the desired shape. However, in addition to the high level of waste involved in milling techniques [10], the high hardness of $\mathrm{CoCr}$ results in extensive wear of milling components when cutting a fully sintered CoCr block [11]. This problem can be alleviated by using a low-stress subtractive technique on softer, wax-bound $\mathrm{CoCr}$ powder milling blocks known as soft-milling (SM). These CoCr blocks are made of evenly distributed CoCr powder held together using a binder material (1-2\% of composition) that is burnt off during the sintering stage of the alloy. The densification that occurs during this process raises the material to its optimal strength [12].

Another CAM manufacturing process is 3D printing or additive manufacturing technology. The low-energy layering process bypasses the physical issues involved with hard machining of alloys, greatly reducing component stress, and also significantly reducing material waste $[10,11]$. Another advantage is the lack of limitation for the size of prosthesis. This is because milling and casting techniques are limited by size of the block or the investment chamber, hence allowing additive manufacturing to be used for fabrication of single-piece maxillofacial model or metallic prostheses [13]. One method to 3D print CoCr alloy is by a laser sintering (LS) process, where a bed of CoCr powder is sintered layer by layer to form a larger structure. Although 3D laser sintering and soft-milling techniques offer alternative low-stress manufacturing of $\mathrm{CoCr}$ prosthetic frameworks, there are relatively few published studies that report on the physical properties of LS and SM manufacturing methods using a standardized methodology [6]. Furthermore, little has been published contrasting those two low-stress manufacturing methods to each other. The aims of this research were to contrast the physical properties of soft-milled (SM CoCr) and laser-sintered (LS CoCr) cobalt-chromium powder with similar composition using standardized techniques to deduce properties important for manufacturing of dental prostheses, including ultimate tensile strength, elastic modulus, proof stress, hardness and fractographic analysis of fracture surface. The null hypothesis is that there is no difference in the mechanical properties between specimens produced using either manufacturing method.

\section{Materials and Methods}

Stereolithographic (STL) models of dumbbells and rectangular plates were designed using computer-aided design software (AutoCAD 2016, Autodesk, San Rafael, CA, USA). The dumbbells were designed in accordance with the ASTM testing standard E8/E8M, the rectangular plates, $\mathrm{n}=1$ per group, were designed with dimensions $8 \times 30 \times 1.5 \mathrm{~mm}$.

Specimens were fabricated using the two manufacturing methods, SM and LS, for both dumbbells (Figure 1) ( $n=20$ per group) and plates ( $n=1$ per group). Table 1 shows the material composition of CoCr powder used for both methods.

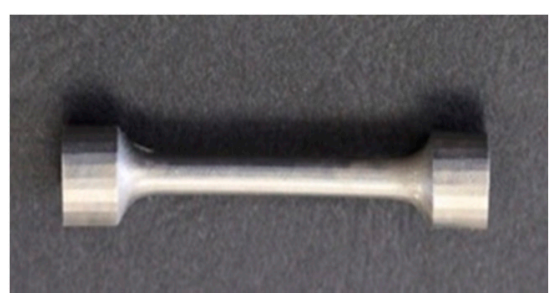

Figure 1. Example of shape of tested dumbbells. 
Table 1. Composition of CoCr powder used in each manufacturing method.

\begin{tabular}{ccccccccc}
\hline Specimens & Brand & Manufacturer & Co & Cr & Mo & Si & Mn & Fe \\
\hline LS CoCr $^{*}$ & CobaltChrome (MP1) & EOS & $60-65 \%$ & $26-30 \%$ & $5-7 \%$ & $<1 \%$ & $<1 \%$ & $<1 \%$ \\
SM CoCr $^{+}$ & Sintron & Amaan Girrbach & $66 \%$ & $28 \%$ & $5 \%$ & $<1 \%$ & $<1 \%$ & $<1 \%$ \\
\hline
\end{tabular}

${ }^{*}$ Laser-sintered cobalt chromium, ${ }^{\dagger}$ soft-milled cobalt chromium.

LS CoCr specimens, which were based on the STL models, were fabricated using an additive manufacturing machine Eosint M270, (EOS, GmBH, Munich, Germany) employing a laser to sinter/3D-print, with a layer thickness of $40 \mu \mathrm{m}$ and $\mathrm{Yb}$-fibre laser $200 \mathrm{~W}$, on a homogenous bed of CoCr powder (EOS CobaltChrome MP1, EOS, Munich, Germany) to the required dimension.

For the SM CoCr specimens, the same STL models as used for the LS group were imported into Ceramill Mind (Amann Girrbach, Koblach, Austria) and milled using 5-Axis Ceramill motion 2 (Amann Girrbach) on a wax-bound CoCr powder block (LOT: 1303054, Sintron, Amann Girrbach) to dimension, then sintered in a furnace at $1500{ }^{\circ} \mathrm{C}$ (Argotherm, Amann Girrbach) to full density following manufacturer's recommendations.

\subsection{Physical Testing of Material}

Fabricated dumbbells were mounted on a Universal Testing Machine (UTM) (Instron 3369, Norwood, MA, USA). The dumbbells were loaded in tension, using a $50 \mathrm{KN}$ load cell, at a loading rate of $1 \mathrm{~mm} / \mathrm{min}$, until fracture. The stress/strain curves were recorded using Bluehill 3 (Instron).

The rectangular plates were polished to a $<0.05 \mu \mathrm{m}$ colloidal silica finish in preparation for nanoindentation testing. Nanoindentations (UMIS, Fischer-Cripps Laboratories, Sydney, Australia) were performed at a static load of $200 \mathrm{mN}$ with $\mathrm{n}=20$ indents across the bulk of the CoCr specimens.

\subsection{Analysis of Fracture Surface}

Three fractured dumbbells from each group (highest, middle and lowest ultimate tensile strengths) were chosen and sectioned while avoiding biological contamination of the fracture surface. Specimens were mounted on aluminum stubs using double-sided carbon tape. The fracture surfaces were viewed in JEOL JSM-6700F field emission scanning electron microscope (SEM) (JEOL Ltd., Tokyo, Japan).

\subsection{Statistical Analysis}

The data were tested using Shapiro and Wilks test, to confirm the assumption of normal distribution of data. Unpaired t-test was used to evaluate statistical significance $(p<0.05)$ (Microsoft Excel version 14.4.7, Microsoft, Redmond, WA, USA).

\section{Results}

\subsection{Mechanical Testing}

Tensile testing results are summarized in Table 2. The testing of dumbbells specimens showed that the elastic modulus was higher for LS CoCr than for SM CoCr samples, however the differences were not statistically significant $(p>0.05)$. The LS CoCr specimens, however, had a statistically significantly higher ultimate tensile strength (UTS) and $0.2 \%$ offset proof stress than that of the SM CoCr specimens $(p<0.05)$.

Nanoindentation results are summarized in Table 3. The results indicated higher hardness values for laser-sintered over milled specimens and closely matched the elastic moduli reported in the tensile testing. 
Table 2. The results of mechanical testing by manufacturing method (standard deviation in brackets).

\begin{tabular}{|c|c|c|c|}
\hline Manufacturing Method & $\begin{array}{l}\text { Elastic Modulus } \\
\text { (GPa) }\end{array}$ & $\begin{array}{l}\text { Ultimate Tensile } \\
\text { Strength (MPa) }\end{array}$ & $\begin{array}{c}0.2 \% \text { Off Set Proof } \\
\text { Stress (MPa) }\end{array}$ \\
\hline $\mathrm{LSCOCr}^{*}$ & $196.2(26.3)$ & $1090.3(27.4)$ & $608.8(23.8)$ \\
\hline $\mathrm{SMCoCr}^{+}$ & $180.4(59.9)$ & $915.9(42.7)$ & $549.4(30.8)$ \\
\hline Stat signific. $(p<0.05)$ & N.S. $\ddagger(p>0.05)$ & $S \S(p<0.01)$ & $S^{\S}(p<0.01)$ \\
\hline
\end{tabular}

* Laser-sintered cobalt chromium, ${ }^{\dagger}$ soft-milled cobalt chromium, ${ }^{\ddagger}$ not statistically significant, ${ }^{\S}$ statistically significant.

Table 3. Elastic modulus and hardness nanoindentation results for both manufacturing methods.

\begin{tabular}{ccccc}
\hline Manufacturing Method & Elastic Modulus (GPa) & S.D. & Hardness (GPa) & S.D. \\
\hline LS CoCr $^{*}$ & 197.0 & 9.2 & 4.4 & 0.2 \\
SM CoCr $^{+}$ & 181.8 & 7.0 & 3.3 & 0.4 \\
\hline
\end{tabular}

${ }^{*}$ Laser-sintered cobalt chromium, ${ }^{\dagger}$ soft-milled cobalt chromium.

\subsection{Fractography}

At lower magnification, $\times 37$ (Figure 2), no obvious origins for the source of fracture could be deduced, and all specimens showed a very homogenous structure.

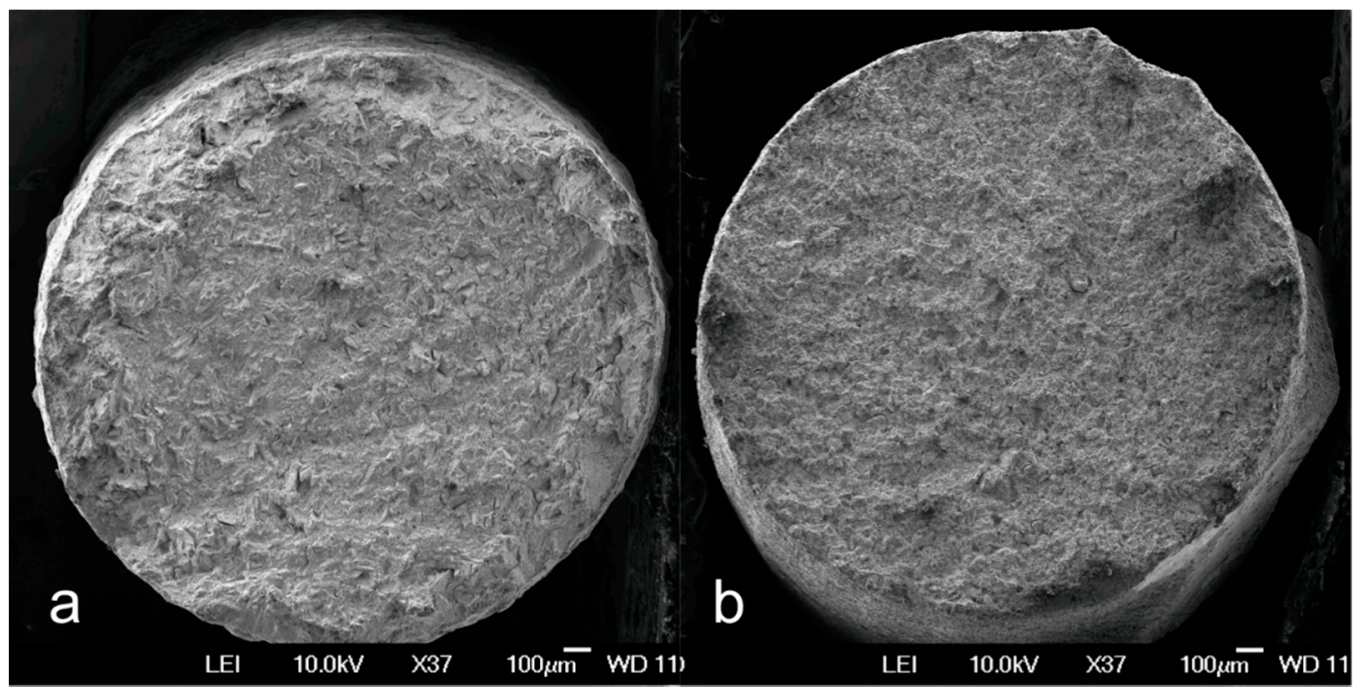

Figure 2. Representative SEM image at $\times 37$ showing (a) fracture surface of LS CoCr dumbbell and (b) fracture surface of SM CoCr dumbbell.

At higher magnification, $\times 1000$, (Figure 3a), the LS CoCr samples appeared to have a very uniform dendritic structure and lattice growth during manufacturing. Specimens also appeared to have undergone failure through brittle fracture mode. In comparison, the SM CoCr specimens (Figure 3b) were found to have numerous well-distributed porosities and microvoids at the fracture surface. The fracture surface showed a mixed failure mode with both brittle decohesion and coalescence of microvoids. Upon closer examinations of the porosities at $\times 3000$ magnification, it was observed that the further the porosity was from the centre of the dumbbell, the larger they became; $\sim 2-3 \mu \mathrm{m}$ at the centre of the dumbbell compared with $\sim 6-7 \mu \mathrm{m}$ closer to the edge (Figure 4). 


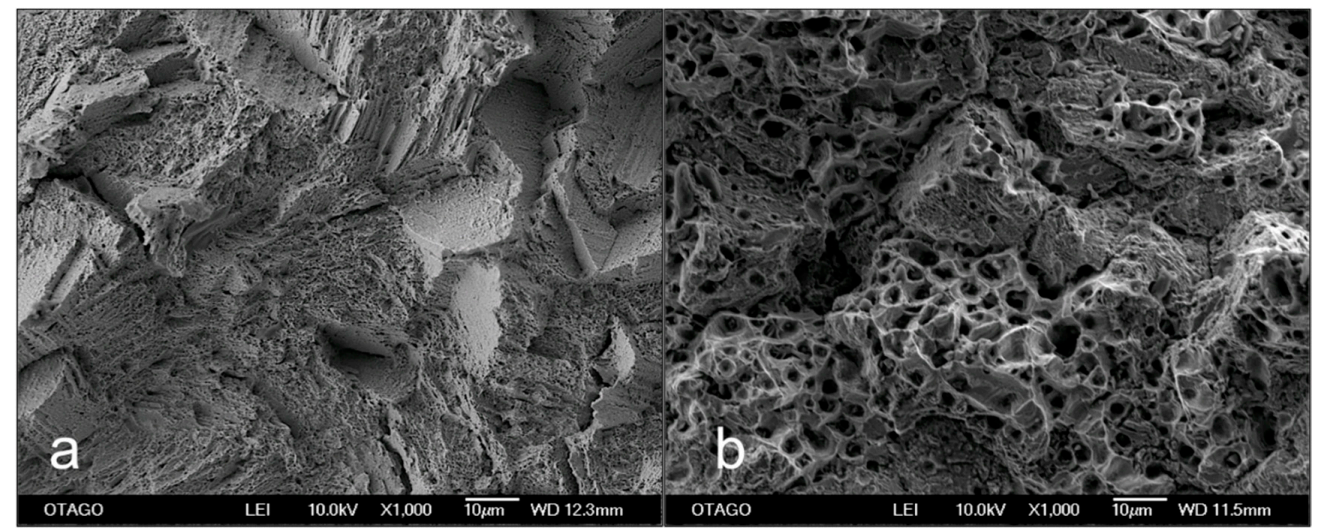

Figure 3. Representative fracture surface SEM $\times 1000$ showing (a) fracture surface of LS CoCr dumbbell and (b) fracture surface of SM CoCr dumbbell.
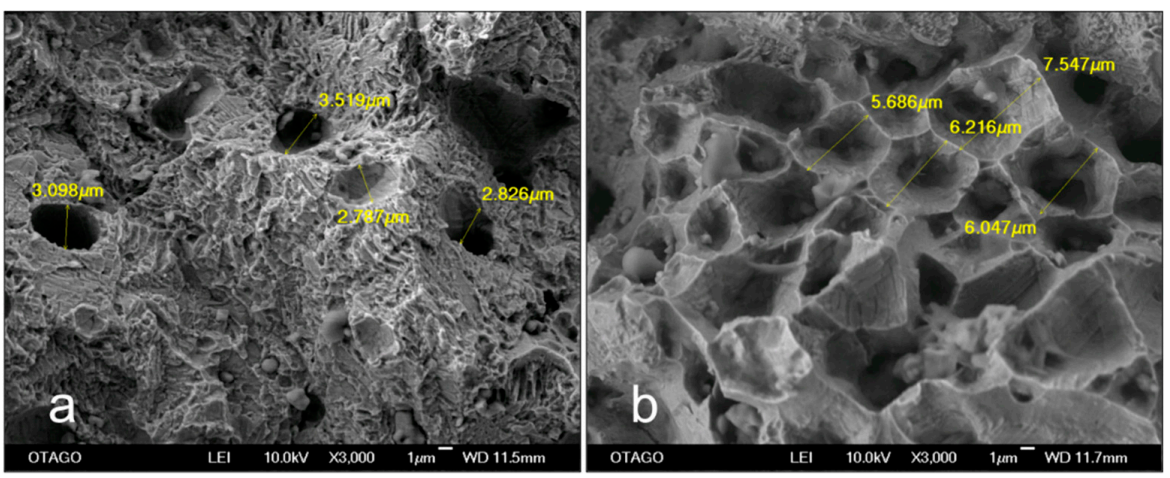

Figure 4. Representative fracture surface of SEM image at $\times 3000$ (a) taken from the centre of the fracture surface, (b) taken from the area adjacent to the edge of the dumbbell. Despite similar magnification being used, the voids are larger at the edge of the dumbbell than at its centre.

\section{Discussion}

In this study, two low-stress CAM CoCr manufacturing techniques were investigated and compared to better understand their respective mechanical properties. The material investigated had a very similar elemental composition, and the mechanical properties of laser-sintered and soft-milled manufactured $\mathrm{CoCr}$ were examined using specimens of specific dimensions in accordance to standardized testing method, ASTM E8. The results of the experiments showed that, with the exception of elastic modulus, LS specimens had significantly better mechanical properties than the SM specimens, hence, the null hypothesis is partially rejected.

There are a number of known shortcomings to in vitro studies because of the difficulty in replicating the dynamic nature of the oral environment [14]. However, standardized in vitro testing may give more information on failure that might not be easy to examine in vivo due to difficulty and expense of examining modes of failures of prostheses in a clinical setting [15]. Another potential shortcoming with this study is that conventional casting of $\mathrm{CoCr}$ method was not directly compared with the other two CAM methods examined. Hence a standardized method was used, testing using ASTM standard and nanoindentation, to be able to compare to results found by other studies using similar methods on other $\mathrm{CoCr}$ manufacturing methods, including traditional lost-wax casting method.

In the early developmental period of laser-sintered manufacturing, the technique was known to produce porous and weak metallic structures [16]. In contrast, our study found LS CoCr specimens were highly satisfactory, having a tensile strength of 1090.3 (27.4) MPa, more than three times higher than the recommended $300 \mathrm{MPa}$ for substructures of CoCr prostheses [17]. Similarly, the process of soft 
machining then sintering of $\mathrm{CoCr}$ also produced specimens with high tensile strength, 915.9 (42.7) $\mathrm{MPa}$, albeit statistically significantly lower than the reported LS CoCr UTS value $(p<0.05)$.

Another important property is the $0.2 \%$ proof stress, which indicates the point at which a material undergoes transition from elastic to plastic deformation. This is particularly important with long-span frameworks which can undergo high flexural bending force [17]. In this study, both LS CoCr and SM CoCr specimens exceeded the recommended $0.2 \%$ proof stress, of $250 \mathrm{MPa}$ (ISO 9693), with results of 608.8 (23.8) $\mathrm{MPa}$ and 549.4 (30.8) $\mathrm{MPa}$, respectively. However, again LS CoCr specimens were statistically significantly higher than SM CoCr specimens $(p<0.05)$.

Elastic moduli for the specimens were examined using two methods; tensile testing and nanoindentation (Tables 2 and 3). Both CAM techniques produced similar values and both methods exceeded the recommended elastic modulus values for long-span prostheses, $180 \mathrm{GPa}$ [5]. These results confirm that either method can be used to accurately deduce the elastic modulus for metallic specimens.

Fractographical analysis of surfaces is essential when trying to explain the microstructure basis for observed mechanical properties [18]. The laser-sintered specimens were very uniform with a well-developed appearance including a typical regular $\mathrm{CoCr}$ dendritic structure. In contrast, the SM $\mathrm{CoCr}$ specimens had what appeared to be voids or pores ranging in size from 2 to $8 \mu \mathrm{m}$ (Figure 4). This phenomenon has been noted by other authors and is due to the escape of the binding polymer during the sintering process of the powder metal blocks [19]. In this study, we found that these pores increased in size the further the area was from the centre of the shaft of the dumbbell and this is likely due to the aggregation and increase in volume of escaping polymer as it leaves the centre of the specimens. The presence of pores and other microdefects has also been shown to decrease the elastic modulus, UTS and proof stress values of overall structure [20]. This corroborates the results observed in this study where the more porous SM CoCr specimens exhibited lower physical properties than the more uniformly dense LS CoCr specimens.

The results obtained for the automated SM and LS techniques can be compared with different manufacturing methods reported in other studies that used similar testing methods as per ISO E8, nanoindentation and SEM examination of fractured surfaces. Cast $\mathrm{CoCr}$, while technique-sensitive and more labour-intensive than CAM technique, is reported to have lower UTS values ranging from 700 to $800 \mathrm{MPa}$ [21-23] and lower $0.2 \%$ proof stress values than LS CoCr SM but higher $0.2 \%$ proof stress values than $\mathrm{CoCr}, 590 \mathrm{MPa}$ [21]. Elastic modulus and hardness values are reported to be comparable to LS; $192.5 \mathrm{GPa}$ and $3.7 \mathrm{GPa}$, respectively, for cast $\mathrm{CoCr}$ [24]. The biggest issue with casting $\mathrm{CoCr}$ remains the unpredictable nature and increased risk of defects forming during penetration of the refractory mould and solidification of the metal during casting, leading to shrinkage deformation of the framework [24], thereby increasing the risk of premature fracture and remaking the prosthesis.

The findings of this study were similar to others published on the topic that did not use similar testing methods. Generally, it was found that LS CoCr had a much more homogenous structure when compared with cast $\mathrm{CoCr}$ [25]. Similarly, UTS and $0.2 \%$ proof stress were found to be higher for LS than for either milled [26] or cast [7,27] CoCr. In comparison, elastic modulus data were usually found to be higher for cast than for LS CoCr [26,28]. Some of the limitations of these studies however are that they did not use $\mathrm{CoCr}$ with similar elemental composition for each of the manufacturing methods and they used smaller samples sizes $(n=6)[26,27]$, and/or used nonstandardized testing methodology $[7,28]$.

Based on the findings of this study, LS CoCr techniques appear to allow for production of a highly homogenous microstructure and dense final substructures for dental prostheses when compared with SM specimens. However, both low-energy CAD/CAM CoCr manufacturing methods produced structures with physical properties far exceeding recommended minimum standards for use in long-span implant- or tooth-supported prostheses in addition to more complex maxillofacial prostheses.

\section{Conclusions}

- Laser sintering manufacturing produces specimens that have superior ultimate tensile strength and proof stress than specimens produced by soft-milled manufacturing method. 
- Elastic modulus for $\mathrm{CoCr}$ can be calculated equally correctly using tensile testing and nanoindentation.

- Soft milling of $\mathrm{CoCr}$ does produce structures with small porosities throughout, likely due to escaping binding polymer.

- Those porosities contribute to reduced ultimate tensile strength and proof stress of soft-milled CoCr.

- Laser sintering and soft milling manufacturing techniques both produce $\mathrm{CoCr}$ structures with highly satisfactory mechanical properties.

Author Contributions: A.B.: Principle investigator, formulated the original idea for the research, undertook bulk of the writing for this article and performing the experiments. K.C.L.: Carried out some of the experiments described, helped with developing the methodology, interpretation of results and statistical analysis as well as with writing the article. B.A.-A.: Helped with developing the methodology and interpretation of the results as well as with proof reading the writing the article. K.L.: Helped with developing the methodology, writing of the article as well as proof-reading. J.N.W.: Primary supervisor, helped in developing methodology, proof reading as well as providing the equipment for the experiment. All authors have read and agreed to the published version of the manuscript.

Funding: Sir John Walsh Research Institute Fuller Grant.

Conflicts of Interest: The authors declare no conflict of interest.

\section{References}

1. Abduo, J.; Lyons, K. Rationale for the Use of CAD/CAM Technology in Implant Prosthodontics. Int. J. Dent. 2013, 2013, 1-8. [CrossRef]

2. Roberts, H.W.; Berzins, D.W.; Moore, B.K.; Charlton, D.G. Metal-Ceramic Alloys in Dentistry: A Review. J. Prosthodont. 2009, 18, 188-194. [CrossRef]

3. Anusavice, K.J.; Shen, C.; Rawls, H.R. (Eds.) Phillips' Science of Dental Materials, 12th ed.; Elsevier Health Sciences: London, UK, 2012.

4. Barucca, G.; Santecchia, E.; Majni, G.; Girardin, E.; Bassoli, E.; Denti, L.; Gatto, A.; Iuliano, L.; Moskalewicz, T.; Mengucci, P. Structural characterization of biomedical $\mathrm{Co}-\mathrm{Cr}-\mathrm{Mo}$ components produced by direct metal laser sintering. Mater. Sci. Eng. C 2015, 48, 263-269. [CrossRef]

5. Wataha, J.C. Alloys for prosthodontic restorations. J. Prosthet. Dent. 2002, 87, 351-363. [CrossRef]

6. Barazanchi, A.; Li, K.C.; Al-Amleh, B.; Lyons, K.; Waddell, J.N. Additive Technology: Update on Current Materials and Applications in Dentistry. J. Prosthodont. 2016, 26, 156-163. [CrossRef]

7. Choi, Y.-J.; Koak, J.-Y.; Heo, S.-J.; Kim, S.-K.; Ahn, J.-S.; Park, D.-S. Comparison of the mechanical properties and microstructures of fractured surface for $\mathrm{Co}-\mathrm{Cr}$ alloy fabricated by conventional cast, 3-D printing laser-sintered and CAD/CAM milled techniques. J. Korean Acad. Prosthodont. 2014, 52, 67-78. [CrossRef]

8. Yamanaka, K.; Mori, M.; Chiba, A. Nanoarchitectured Co-Cr-Mo orthopedic implant alloys: Nitrogen-enhanced nanostructural evolution and its effect on phase stability. Acta Biomater. 2013, 9 , 6259-6267. [CrossRef]

9. Li, K.C.; Prior, D.J.; Waddell, J.N.; Swain, M.V. Comparison of the microstructure and phase stability of as-cast, $\mathrm{CAD} / \mathrm{CAM}$ and powder metallurgy manufactured $\mathrm{Co}-\mathrm{Cr}$ dental alloys. Dent. Mater. 2015, 31, e306-e315. [CrossRef] [PubMed]

10. Van Noort, R. The future of dental devices is digital. Dent. Mater. 2012, 28, 3-12. [CrossRef] [PubMed]

11. Abduo, J.; Lyons, K.; Bennamoun, M. Trends in Computer-Aided Manufacturing in Prosthodontics: A Review of the Available Streams. Int. J. Dent. 2014, 2014, 1-15. [CrossRef] [PubMed]

12. Krug, K.-P.; Knauber, A.W.; Nothdurft, F.P. Fracture behavior of metal-ceramic fixed dental prostheses with frameworks from cast or a newly developed sintered cobalt-chromium alloy. Clin. Oral Investig. 2014, 19, 401-411. [CrossRef]

13. Koutsoukis, T.; Zinelis, S.; Eliades, G.; Al-Wazzan, K.; Al Rifaiy, M.; Al Jabbari, Y.S. Selective Laser Melting Technique of Co-Cr Dental Alloys: A Review of Structure and Properties and Comparative Analysis with Other Available Techniques. J. Prosthodont. 2015, 24, 303-312. [CrossRef]

14. Kelly, J.R.; Benetti, P.; Rungruanganunt, P.; Della Bona, A. The slippery slope-Critical perspectives on in vitro research methodologies. Dent. Mater. 2012, 28, 41-51. [CrossRef] 
15. Anusavice, K.J.; Kakar, K.; Ferree, N. Which mechanical and physical testing methods are relevant for predicting the clinical performance of ceramic-based dental prostheses? Clin. Oral Implant. Res. 2007, 18, 218-231. [CrossRef]

16. Kathuria, Y. Microstructuring by selective laser sintering of metallic powder. Surf. Coat. Technol. 1999, 116, 643-647. [CrossRef]

17. Wataha, J.C.; Messer, R.L. Casting alloys. Dent. Clin. N. Am. 2004, 48, 499-512. [CrossRef]

18. Gokhale, A.; Patel, G. Quantitative fractographic analysis of variability in tensile ductility of a squeeze cast Al-Si-Mg base alloy. Mater. Charact. 2005, 54, 13-20. [CrossRef]

19. Salak, A. Ferrous Powder Metullargy; Cambridge International Science Publishing: Cambridge, UK, 1997.

20. Chawla, N.; Deng, X. Microstructure and mechanical behavior of porous sintered steels. Mater. Sci. Eng. A 2005, 390, 98-112. [CrossRef]

21. Kilner, T. Static mechanical properties of cast and siner-annealed cobalt-chromium surgical implants. J. Mater. Sci. 1986, 21, 1349-1356. [CrossRef]

22. Li, B.; Mukasyan, A.S.; Varma, A. Combustion synthesis of CoCrMo orthopedic implant alloys: Microstructure and properties. Mater. Res. Innov. 2003, 7, 245-252. [CrossRef]

23. Denti, L. Evaluation of performance of cast and laser-sintered cr-co alloys for dental applications. Int. J. Appl. Eng. Rest. 2017, 12, 3801-3809.

24. Li, K.C. Microstructure and Phase Stability of Three Dental Cobalt Chromium Alloys Used for Porcelain-Fused-to-Metal Restorations during Thermal Processing. Ph.D. Thesis, University of Otago, Dunedin, New Zealand, 2015.

25. Xiang, N.; Xin, X.-Z.; Chen, J.; Wei, B. Metal-ceramic bond strength of Co-Cr alloy fabricated by selective laser melting. J. Dent. 2012, 40, 453-457. [CrossRef] [PubMed]

26. Kim, H.R.; Jang, S.-H.; Kim, Y.K.; Son, J.S.; Min, B.K.; Kim, K.; Kwon, T.-Y. Microstructures and Mechanical Properties of Co-Cr Dental Alloys Fabricated by Three CAD/CAM-Based Processing Techniques. Materials 2016, 9, 596. [CrossRef] [PubMed]

27. Wu, L.; Zhu, H.; Gai, X.; Wang, Y. Evaluation of the mechanical properties and porcelain bond strength of cobalt-chromium dental alloy fabricated by selective laser melting. J. Prosthet. Dent. 2014, 111, 51-55. [CrossRef] [PubMed]

28. Stawarczyk, B.; Eichberger, M.; Hoffman, R.; Noack, F.; Schweiger, J.; Edelhoff, D.; Beuer, F. A novel cad/cam base metal compared to conventional cocrmo alloys:An in-vitro study of the long-term. Oral Health Dent. Manag. 2014, 13, 17.

(C) 2020 by the authors. Licensee MDPI, Basel, Switzerland. This article is an open access article distributed under the terms and conditions of the Creative Commons Attribution (CC BY) license (http://creativecommons.org/licenses/by/4.0/). 